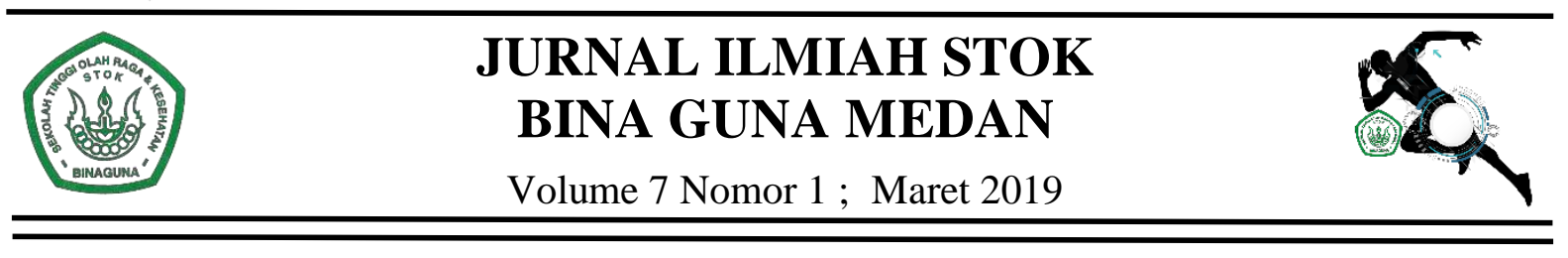

\title{
PENGEMBANGAN PERALATAN MODIFIKASI ATLETIK PADA PEMBELAJARAN PJOK TINGKAT SEKOLAH DASAR
}

\author{
Khairul Usman ${ }^{1}$ Rinaldi Aditya ${ }^{2}$, Boby Helmi ${ }^{3}$ \\ ${ }^{1}$ Universitas Negeri Medan \\ ${ }^{2,3}$ Sekolah Tinggi Olahraga dan Kesehatan Bina Guna \\ email : khairulusmanunimed@gmail.com
}

\begin{abstract}
ABSTRAK
Standar peralatan atletik sangat tidak memungkinkan jika diberikan pada siswa usia sekolah dasar, sebab untuk postur tubuh dan kemampuan beban berat masih belum layak diterapkan pada proses pembelajaran sekolah dasar. Prioritas dalam pembelajaran khususnya materi atletik adalah mengenalkan dengan baik dan mengupayakan agar siswa dapat melakukan tenik dan gaya yang benar dalam melakukan gerakan setiap nomor atletik.Tujuan penelitian pengembangan peralatan modifikasi atletik adalah melatih guru untuk terampil melakukan modifikasi dalam pembelajaran PJOK khususnya materi atletik dengan bahan yang mudah dijumpai, mudah untuk diolah secara sederhana, praktis, dan ekonomis, sehingga sangat tepat digunakan oleh seluruh kalangan sekolah khususnya sekolah dasar.Tahapan pembuatan peralatan modifikasi atletik adalah dengan menggunakan desain penelitian pengembangan atau research and development $(R n D)$ melalui Intructional design (desain pembelajaran) dengan pendekatan ADDIE (analysis, design, development, implementation, dan evaluation).Produk penelitian yang dihasilkan berupamedia audio visual dalam bentuk Corps Diplomatique(CD) merupakan hasil perkembangan teknologi yang dikembangkan berupa gambar bersuara untuk memberi kemudahan dalam proses pembuatan peralatan modifikasi atletik.
\end{abstract}

Kata Kunci : Pengembangan, Peralatan, Modifikasi, Atletik, PJOK

\section{PENDAHULUAN}

Pendidikan jasmani di sekolah dikenal dengan istilah Pendidikan Jasmani Olahraga dan Kesehatan (PJOK) dan menciptakan interaksi antara pengajar dan peserta didik dalam pembelajaran gerak mencapai tujuan bersama. Pembelajaran PJOK identik dengan kebugaran fisik dan juga berkaitan dengan kondisi psikis yang berasal dari manfaat akibat proses yang dijalankan pendidikan jasmani. Undangundang Tentang Sistem Keolahrgaan Nasional Tahun 2005 Pasal 1 ayat 11 menerangkan bahwa "Olahraga pendidikan adalah pendidikan jasmani dan olahraga yang dilaksanakan sebagai bagian proses pendidikan yang teratur dan berkelanjutan untuk memperoleh pengetahuan, kepribadian, keterampilan, kesehatan, dan kebugaran jasmani”.

Pendidikan jasmani adalah proses pendidikan yang memanfaatkan aktivitas jasmani yang direncanakan secara sistematis bertujuan untuk mengembangkan dan meningkatkan individu secara organik, neuromaskuler, 
perseptual, kognitif, dan emosional, dalam kerangka sistem pendidikan nasional. Pendidikan jasmani merupakan bagian penting dari proses pendidikan. Artinya, pendidikan jasmani bukan hanya dekorasi atau ornament yang ditempel pada program sekolah sebagai alat untuk membuat anak sibuk. Tetapi pendidikan jasmani adalah bagian penting dari pendidikan. Melalui pendidikan jasmani yang diarahkan dengan baik, anak akan mengembangkan keterampilan yang berguna bagi pengisian waktu senggang, terlibat dalam aktivitas yang kondusif untuk mengembangkan hidup sehat, berkembang secara sosial, dan menyumbang pada kesehatan fisik dan mentalnya(Rosdiani, 2013).

Proses pembelajaran pendidikan jasmani guru diharapkan mengajar berbagai keterampilan gerak dasar, teknik, dan model permainan dan olahraga, internalisasi nilai-nilai (sportivitas, kejujuran, kerjasama) serta pembiasaan pola hidup sehat. Pelaksanaannya bukan melalui pembelajaran konvensional di dalam kelas yang bersifat kajian teoritis, namun melibatkan unsur fisik, mental, intelektual, emosi, dan sosial. Aktivitas yang diberikan dalam pembelajaran harus mendapatkan sentuhan didaktik-metodik, sehingga aktivitas yang dilakukan dapat mencapai tujuan pembelajaran(Rahayu, 2013).

Materi pendidikan jasmani terdiri dari permainan bola kecil, permainan bola besar, atletik, senam, kegiatan air, dan pola hidup kesehatan. Setiap peserta didik harus memenuhi kualifikasi kompetensi materi dengan proses pengajaran yang disampaikan oleh guru Penjas. Materimateri yang terdapat pada Penjas pada umumnya sama dalam tiap satuan pendidikan, namun yang membedakan adalah kajian-kajian dan pendalam yang disesuaikan dengan tingkatan satuan pendidikan.
Atletik adalah salah satu mata pelajaran dasar untuk diterapkan pada siswa Sekolah Dasar sejak kelas 4,5, dan 6. Atletik merupakan olahraga induk dalam mewujudkan cabang-cabang olahraga lain karena di dalam atletik terdapat teknik gerak lari, lompat, dan lempar. Seluruh gerakan dalam atletik meliputi seluruh gerakan tubuh dan berkembang pada olahraga lain seperti sepak bola, bulutangkis, dan lainnya.

Atletik sangat penting diterapkan pada siswa Sekolah Dasar dan menjadi tanggung jawab sekolah untuk dapat memfasilitasi kebutuhan pada setiap nomor atletik seperti ; 1) nomor lari harus terdapat lintasan dan pendukung lainnya seperti gawang, 2) nomor lompat meliputi lompat jauh, lompat tinggi, dan lompat galah, dan lompat jingkat, 3) nomor lempar meliputi lempar lembing, tolak peluru, lempar cakram, dan lontar martil.

Kemampuan atletik yang merupakan kemampuan gerakan dasar dari setiap aktivitas olahraga pada umumnya sangatlah penting dikuasai untuk memperoleh gerakan-gerakan yang harmonis saat melakukan kegiatan. Aktivitas atletik membutuhkan kajian ulang tentang didaktik dan metodik dalam pengajaran dan pelatihan atletik (Sidik, 2014:1). Standar peralatan atletik sangat tidak memungkinkan jika diberikan pada siswa usia sekolah dasar, sebab untuk postur tubuh dan kemampuan beban berat masih belum layak diterapkan pada proses pembelajaran sekolah dasar. Prioritas dalam pembelajaran khususnya materi atletik adalah mengenalkan dengan baik dan mengupayakan agar siswa dapat melakukan tenik dan gaya yang benar dalam melakukan gerakan setiap nomor atletik, dan oleh sebab itu diperlukan modifikasi alat atletik yang dapat digunakan oleh siswa sekolah dasar. 
Modifikasi peralatan atletik merupakan pembuatan media sebagai alat bantu pada pembelajaran atletik.

Kata media berasal dari bahasa Latin medius yang secara harfiah berarti "tengah", "perantara" atau "pengantar". Gerlach dan Ely menjabarkan bahwa media dapat dipahami secara garis besar adalah manusia, materi, atau kejadian yang membangun kondisi yang membuat siswa mampu memperoleh pengetahuan, keterampilan, atau sikap. Batasan lain dikemukakan oleh para ahli yakni AECT (Association of Education and Communication Technology, 1977) memberi batasan tentang media sebagai segala bentuk dan saluran yang digunakan untuk pesan atau informasi. Media juga sering diganti dengan kata mediator menurut Fleming, 1987(dalam Arsyad, 2009) adalah penyebab atau alat yang turut campur tangan dalam dua pihak dan mendamaikannya. Pengertian beberapa ahli sebagaimana penjelasan yang demikian dapat disimpulkan bahwa media adalah sebuah alat bantu dalam menyampaikan pesan, alat bantu dapat dilakukan dengan benda hidup maupun mati, dengan maksud tercapainya sebuah informasi atau pesan yang akan disampaikan.

Standar peralatan atletik sangat tidak memungkinkan jika diberikan pada siswa usia sekolah dasar, sebab untuk postur tubuh dan kemampuan beban berat masih belum layak diterapkan pada proses pembelajaran sekolah dasar. Prioritas dalam pembelajaran khususnya materi atletik adalah mengenalkan dengan baik dan mengupayakan agar siswa dapat melakukan teknik dan gaya yang benar dalam melakukan gerakan setiap nomor atletik, dan oleh sebab itu diperlukan modifikasi alat atletik yang dapat digunakan oleh siswa Sekolah Dasar.

\section{METODE PENELITIAN}

Pelaksanaan penelitian dirancangan menggunakan desain penelitian pengembangan atau research and development (RnD)berupa modifikasi peralatan atletik pada pembelajaran PJOK tingkat sekolah dasar. Penelitian ini dilakukan sebagai pengembangan dari produk kids' athletics dan Peralatan Olahraga Anak (POA) Kemenpora yang sebelumnya telah ada. Pengembangan produk melalui penelitian ini akan diberi nama "Peralatan Modifikasi Atletik" dirancang melalui modifikasi alat yang praktis dan ekonomis dalam mencapai keefektifan dalam proses pembelajaran.

Prosedur Penelitian dengan menggunakanIntructional design (desain pembelajaran) dengan pendekatan ADDIE, yang merupakan perpanjangan dari analysis, design, development, implementation, dan evaluation(Sugiyono, 2016).

1) Analysis : Melakukan analisis pada peralatan atletik yang akan dimodifikasi

2) Design: Perancangan Peralatan Modifikasi Atletik

3) Development dan Implemetation : Pembuatan dan Penggunaan (Pengujian Produk)

4) Evaluation : Menilai dan Revisi Produk

Teknik pengumpulan data dilakukan dengan 4 level yaitu : 1) Data "analysis" untuk mengetahui masalah yang terjadi pada pembelajaran PJOK materi atletik di Sekolah Dasar, 2) data "design" untuk merancang sebuah produk sebagai upaya pemecahan masalah,3)data "development and Implementation" adalah pembuatan dan penggunaan produk untuk dilakukan pengujian produk. 4) data 
"evaluation" adalah data penilaian produk dan akan memberikan keterangan tentang kelayakan Produk untuk digunakan.

Instrumen yang digunakan untuk mengumpulkan data adalah observasi (pengamatan), dokumentasi, Forum Group Discussion (FGD), wawancara, dan angket. Pengumpulan data dengan teknik observasi dan dokumentasi digunakan pada pengumpulan data level 1 , dan instrumen angket dan wawancara digunakan untuk memperoleh datapada level 2 sampai level 4.Instrumen pengumpul data dengan observasi dan dokumentasi digunakan sebelum pembuatan produk artinya data yang diperoleh dari instrumen tersebut dijadikan acuan dalam membuat produk. Instrumen angket dan wawancara digunakan saat perancangan dan penyelesaian produk sehingga akan diperoleh hasil kelayakan produk.

Data yang diperoleh melalui kegiatan uji coba diklasifikasikan menjadi dua, yaitu data kuantitatif dan data kualitatif.Data kualitatif berupa kritik saran yang dikemukakan oleh ahli media, ahli materi, dan siswa kemudian dihimpun untuk perbaikan.Teknik analisis data kuantitatif dalam penelitian ini menggunakan analisis stastistik deskriptif, yang berupa pernyataan sangat kurang, kurang, cukup baik, baik dan sangat baik yang diubah menjadi data kuantitatif dengan skala 5 yaitu dengan penskoran dai angka 1 sampai 5. Langkah-langkah dalam analisis data antara lain: mengumpulkan data kasar, pemberian skor, skor yang diperoleh kemudian dikonversikan menjadi nilai dengan skala 5. Selanjutnya untuk menghitung persentase menggunakan rumus di bawah ini:

$$
\begin{array}{ll} 
& P=\frac{f}{n} \times 100 \\
\text { Keterangan: } & f=\text { Frekuensi Subjek } \\
& n=\text { Jumlah Keseluruhan }
\end{array}
$$

uji coba

$$
\mathrm{P}=\text { Presentase hasil subjek }
$$

Untuk mengambil keputusan menggunakan kriteria yang ditetapkan oleh Sutrisno Hadi sebagai berikut:

Tabel Kriteria Untuk Menentukan Presentase

\begin{tabular}{|c|l|l|}
\hline Nilai & Skala Penilaian & Kualifikasi \\
\hline 1 & $0-55 \%$ & Sangat Kurang Baik \\
\hline 2 & $56-65 \%$ & Kurang Baik \\
\hline 3 & $66-80 \%$ & Baik \\
\hline 4 & $81-100 \%$ & Sangat Baik \\
\hline
\end{tabular}

(Sumber:Hadi, 2004)

\section{HASIL DAN PEMBAHASAN}

Pengembangan peralatan modifikasi atletik pembelajaran PJOK (Pendidikan Jasmani Olahraga dan Kesehatan) memiliki dasar pada temuan yang terjadi bahwa peralatan atletik tidak sepenuhnya terdapat di Sekolah Dasar sehingga membuat kegiatan pembelajaran materi Atletik menjadi terbatas dan bahkan dilewatkan untuk tidak dipelajari. Upaya guru dalam mengembangkan peralatan atletik di Sekolah Dasar mengalami keterbatasan dalam meluangkan kreativitas agar unsurunsur yang menjadi kompetensi materi atletik dapat terwujud.

Tahap permulaan dalam pengembangan produk adalah dengan melakukan analysisyaitu analisis peralatan atletik yang terdapat di skeolah dasar kemudian nomor-nomor pada olahraga atletik. Analisis dilakukan oleh tim peneliti, satu orang mahasiswa, 3 orang pakar pendidikan jasmani sekolah dasar. Hasil analisis diperoleh bahwa materi atletik meliputi beberapa nomor yaitu :

1. Nomor lari yang terdiri dari lari jarak pendek, menengah, jauh, estafen, dan jalan cepat. Peralatan yang dikembangkan adalah lintasan dan beberapa alat pendukungnya. Peralatan 
yang dikembangkan adalah sebagai berikut :

a. Lintasan Lari : Bahan yang modifikasi adalah tali plastik warna atau tali lainnya dan dibuat seperti lintasan lari sebenarnya. Bentuk lintasan lari ini akan membuat siswa tertarik untuk melakukan lari dan memberikan pemahaman siswa terhadap bentuk lintasan lari yang sebenarnya.

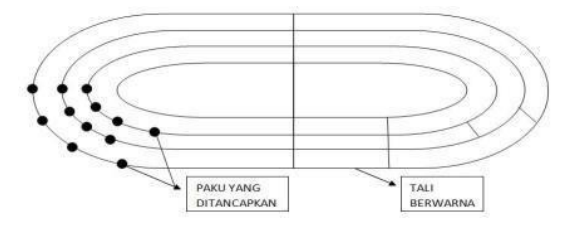

Gambar 1. Rancangan Modifikasi Lintasan

b. Gawang : Modifikasi Gawang (lari) : Bahan yang dimodifikasi terbuat dari kardus yang dibentuk segitiga.Ukuran dapat disesuaikan atau dengan ketinggian $60-90 \mathrm{~cm}$.

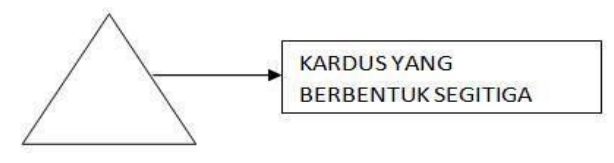

Gambar 2. Rancangan Modifikasi

Gawang

c. Modifikasi Tongkat Estafet : Bahan yang dimodifikasi terbuat dari kayu (gagang sapu bekas) atau pipa air.Ukuran panjang 30 $\mathrm{cm}$ dan diameter $2,6 \mathrm{~cm}$.

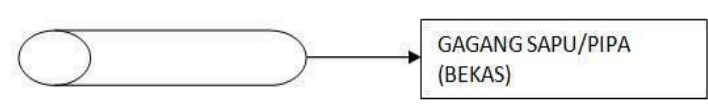

Gambar 3. Rancangan Modifikasi Tongkat Estafet
2. Nomor lompat yang terdiri dari lompat jauh, lompat galah, dan lompat tinggi. Peralatan yang dikembangkan adalah sebagai berikut :

a. Lompat jauh : Bahan yang dimodifikasi terbuat dari kardus (kotak).Ukuran per satu kardus (kotak) : panjang $1 \mathrm{~m}$ dan tinggi 30 $\mathrm{cm}$.

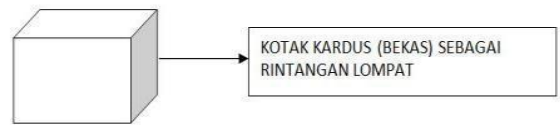

Gambar 4. Rancangan Modifikasi Lompat Jauh

b. Lompat Galah : Bahan yang dimodifikasi terbuat dari bambu/stok Pramuka sebagai galah dan kardus Nilai (Skor).Ukuran panjang galah $2 \mathrm{~m}$ dan diameter 4 $\mathrm{cm}$, pada tiap nilai diberi jarak 1,5 $\mathrm{m}$.

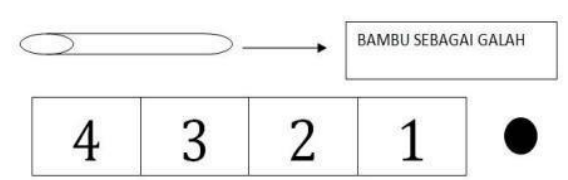

Gambar 5. Rancangan Modifikasi Lompat Galah

c. Lompat Tinggi : Bahan yang dimodifikasi terbuat dari karet gelang/ban, dinding skor/nilai, dan orang.Dinding skor terdiri dari 5 kategori dan masing-masing jaraknya $0,5 \mathrm{~cm}$, panjang karet $5 \mathrm{~m}$ (tanpa ditarik).

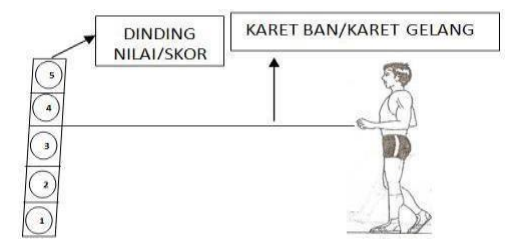

Gambar 6. Rancangan Modifikasi Lompat Tinggi 
3. Nomor lempar yang terdiri dari tolak pelur, lempar lembing, lempar cakram, dan lontar martil. Peralatan yang dikembangkan adalah sebagai berikut :

a. Tolak Peluru : Bahan yang dimodifikasi terbuat dari bola warna berukuran diameter $6 \mathrm{~cm}$, kemudian dibelah atau diberi lubang sebesar batu yang akan dimasukkan. Bola dapat diisi dengan pasir atau batu. Ukuran bola $6 \mathrm{~cm}$ dan berat $2-4 \mathrm{~kg}$.
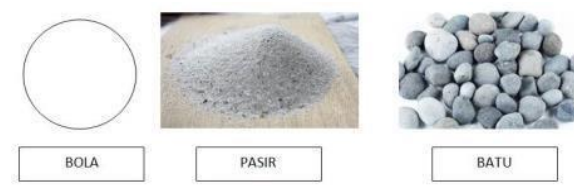

Gambar 7. Rancangan Modifikasi Tolak Peluru

b. Lempar Lembing: Bahan yang dimodifikasi terbuat dari botol kosong yang dibentuk seperti roket.Ukuran botol : panjang bekisar 25-50 cm dan diameter 4$10 \mathrm{~cm}$.

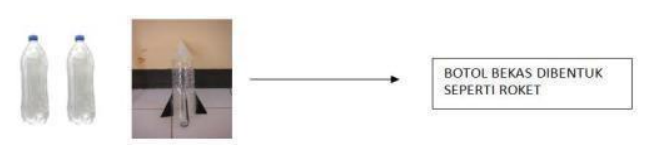

Gambar 8. Rancangan Modifikasi Lempar Lembing

c. Lempar Cakram: dua piring yang disatukan atau posisi saling menutup.Ukuran piring : ukuran diameter bekisar $20-25 \mathrm{~cm}$ dan tinggi tengah $5-6 \mathrm{~cm}$.

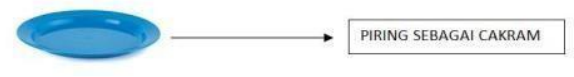

Gambar 9. Rancangan Modifikasi Lempar Cakram d. Lontar Martil: bola warna yang diisi dengan pasir dan dibentuk ikatan sebagai pegangan.Ukuran bola $6 \mathrm{~cm}$ dan berat $2-4 \mathrm{~kg}$, panjang tali disesuaikan atau dapat dibuat dengan ukuran panjang tali $40 \mathrm{~cm}$, dan dibuat batas pegangannya sekitar $10 \mathrm{~cm}$.

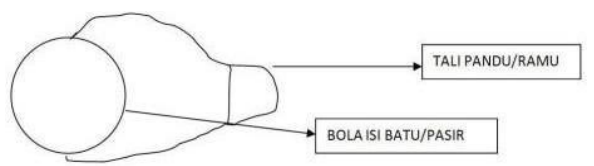

Gambar 10. Rancangan Modifikasi Lontar

Martil

Modifikasi peralatan atletik pada Sekolah Dasar diperagakan oleh oleh Guru Sekolah Dasar dan Siswa Sekolah Dasar sebagai pelaksana pembuatan produk. Produk modifikasi peralatan atletik berbnetuk tutorial yang terdiri dari bahanbahan modifikasi peralatan atletik, teknik pembuatan peralatan, dan cara melakukan praktek materi atletik sesuai dengan kompetensi Pendidikan Jasmani Sekolah Dasar (PJKR) Sekolah Dasar.

Penerapan produk dapat digunakan oleh seluruh guru dan sekolah tingkat sekolah dasar karena pembuatan modifikasi peralatan atletik tidak memiliki tingkat kesulitan yang tinggi. Bahan yang digunakan menggunakan bahan sederhana yaitu bahan yang biasanya ditemui di sekolah seperti kardus, bola plastik, tali rafiah, tali rami, batu kecil, pasir, semen, pisau, gunting, kertas, paku, palu, piring plastik, dan perekat bahan yang dimidofikasi. Proses pembuatanproduk disimulasikan oleh siswa sekolah dasar sehingga memberikan kemudahan dalam memahami pembuatan dan penggunaan peralatan yang dimodifikasi. 


\section{KESIMPULAN}

Pengembangan modifikasi peralatan Atletik untuk tingkat Sekolah Dasar disusun berdasarkan asas kebutuhan yang diperlukan agar pelaksanaan materi Atletik tidak terkendala karena terbatasnya peralatan atau bahkan tidak ada. Konsep utama siswa Sekolah Dasar bahwa Pembelajaran PJOK dimaksud adalah meningkatkan minat belajar gerak siswa agar fisik dapat tumbuh sesuai tingkat perkembangannya, sehingga yang diperlukan adalah keterampilan dasar terhadap teknik pada pembelajaran atletik. Produk modifikasi peralatan atletik adalahCorps Diplomatique media audio visual berupa metode pembuatan modifikasi peralatan atletik dari bahan yang sederhana. Rangkaian isi produk meliputi teknik pembuatan modifikasi peralatan atletik yang terdiri dari : 1) lintasan lari, 2) gawang, 3) estafet, 4) lompat jauh, 5) lompat tinggi, 6) lompat galah, 7) tolak peluru, 8) lempar lembing, 9) lempar cakram, dan 10) lontar martil. Seluruh rangkaian modifikasi dibentuk agar teknik yang akan diajarkan kepada siswa dapat dilakukan dengan perlengkapan yang praktis, efektif, dan ekonomis dengan bahan-bahan yang mudah dijumpai di sekolah.

\section{DAFTAR PUSTAKA}

Arsyad, A. 2009. Media Pembelajaran. Jakarta: PT Grafindo Persada.

Hadi. 2004. Metodologi Research 2. Yogyakarta: Andi Offset.

Rahayu, E. T. 2013. Strategi Pembelajaran Pendidikan Jasmani. Bandung: Alfabeta.

Rosdiani, D. 2013. Perencanaan Pembelajaran dalam Pendidikan Jasmani dan Kesehatan. Bandung: Alfabeta.

Sugiyono. 2016. Metode Penelitian dan Pengembangan (Research and Development). Bandung: Alfabeta. 